\title{
Evaluating the decision to participate in a fair trade model of coffee-producing households in Xuan Truong commune, Da Lat city, Lam Dong province
}

\author{
Nam H. Tran*, \& Han T. N. Tran \\ Faculty of Economics, Nong Lam University, Ho Chi Minh City, Vietnam
}

ARTICLE INFO
Research Paper
Received: November 29, 2019
Revised: December 12, 2019
Accepted: January 09, 2020
Keywords
Coffee production
Fair-trade
Logit model
*Corresponding author
Tran Hoai Nam
Email: hoainam@hcmuaf.edu.vn

\begin{abstract}
Fair trade in coffee production offers an opportunity to improve farmers' position in the market. The study used a logit model with the maximum likelihood estimation method to evaluate the famers' decision to participate in a fair trade coffee production model. Data were collected by directly interviewing 220 farmers in Xuan Truong commune, Da Lat city, Lam Dong province. This commune has applied the fair trade model in coffee production with the brand of Cau Dat coffee. The results of this study showed that the probability of households deciding to participate in the fair trade coffee model was $14.43 \%$. In addition, factors affecting the decision to participate in the fair trade coffee model were householders, education level, area of agricultural land, profitability, awareness of fair trade, desired price of coffee, and agricultural extension. In particular, the farmer's awareness of fair trade and the desired price of coffee had positive impacts on the farmers' participation in a fair trade coffee model.
\end{abstract}

Cited as: Tran, N. H., \& Tran, H. T. N. (2020). Evaluating the decision to participate in a fair trade model of coffee-producing households in Xuan Truong commune, Da Lat city, Lam Dong province. The Journal of Agriculture and Development 19(2), 1-8. 


\title{
Đánh giá quyết định tham gia mô hình thương mại công bằng của nông hộ sản xuất cà phê tại xã Xuân Trường, thành phố Đà Lạt, tỉnh Lâm Đồng
}

\author{
Trần Hoài Nam* \& Trần Thị Ngọc Hân \\ Khoa Kinh Tế, Trường Đại Học Nông Lâm TP.HCM, TP. Hồ Chí Minh
}

\author{
THÔNG TIN BÀI BÁO \\ Bài báo khoa học \\ Ngày nhận: 29/11/2019 \\ Ngày chỉnh sửa: 12/12/2019 \\ Ngày chấp nhận: 09/01/2020

\section{Từ khóa} \\ Mô hình hồi qui logit \\ Sản xuất cà phê \\ Thương mại công bằng \\ *Tác giả liên hệ \\ Trần Hoài Nam \\ Email: hoainam@hcmuaf.edu.vn
}

\section{TÓM TẮT}

Thương mại công bằng trong sản xuất cà phê là tạo cho nông dân cơ hội công bằng để cải thiện vị thế thị trường của họ. Nghiên cứu này đã sử dụng mô hình hồi quy logit với phương pháp ước lượng khả năng tối đa (maximum likelihood estimation) nhằm đánh giá quyết định tham gia mô hình thương mại công bằng của nông hộ sản xuât cà phê. Số liệu được thu thập bằng cách phỏng vấn trực tiếp 222 hộ canh tác cà phê tại xã Xuân Trường, TP. Đà Lạt, tỉnh Lâm Đồng, đây là khu vực đang thực hiện mô hình thương mại công bằng trong sản xuất cà phê với thương hiệu cà phê Cầu Đất. Kết quả nghiên cứu cho thấy, xác suất nông hộ quyết định tham gia sản xuất cà phê theo mô hình thương mại công bằng là $14,43 \%$ và các yếu tố ảnh hưởng đến quyết định tham gia mô hình như tuổi chủ hộ, trình độ học vấn, diện tích, lợi nhuận, nhận thức của nông hộ về thương mại công bằng, mức giá mong muốn và khuyến nông. Trong đó, biến nhận thức của nông hộ và mức giá mong muốn có tác động mạnh đến quyết định tham gia mô hình thương mại công bằng trong sản xuất cà phê.

\section{1. Đắt Vấn Đề}

Cà phê là một trong những nông sản xuất khẩu chủ lực của Việt Nam và hiện tại là nước xuất khẩu cà phê lớn đứng đầu châu Á, thứ hai thế giới. Trong năm 2018, xuất khẩu cà phê đạt 1,88 triệu tấn với giá trị là 3,54 tỷ USD, đóng góp khoảng $15 \%$ tồng xuất khẩu nông sản của cả nước (Vicofa, 2018). Diện tích cây cà phê chủ yếu tập trung tại khu vực Tây Nguyên và theo quy hoạch của Bộ Nông nghiệp và Phát triển nông thôn đến năm 2020 diện tích trồng cà phê của khu vực là 530.000 ha (MARD, 2014). Tuy nhiên, ngành đang phải đối mặt với những thách thức to lớn vì phương pháp canh tác hiện tại và cơ sở hạ tầng đã không bền vững với $90 \%$ diện tích áp dụng phương pháp thâm canh truyền thống, thiếu cây che bóng và cây đai rừng, lạm dụng phân hóa học, thuốc trừ sâu, gây ô nhiễm nước mặt, 40\% diện tích tưới quá yêu cầu làm mực nước ngầm suy giảm (Le, 2017; Nguyen \& Tapan, 2018), do đó ngành cà phê đang tập trung chuyển hướng sang sản xuất cà phê bền vững.

Hiện nay, việc sản xuất cà phê bền vững có chứng nhận quốc tế đang được thực hiện rộng khắp ở Tây Nguyên. Các loại hình cà phê chứng nhận phổ biến là $4 \mathrm{C}, \mathrm{UTZ}$, Rainforest Aliance, và thương mại công bằng. Chương trình chứng nhận cà phê thương mại công bằng được khởi động tại Tây Nguyên vào giữa năm 2008 thông qua một dự án của một số công ty. Tại Lâm Đồng, tính đến năm 2017 đã có trên 4.000 nông hộ tham gia sản xuất cà phê có chứng nhận thương mại công bằng. Tuy nhiên, việc triển khai chứng nhận thương mại công bằng trên cà phê hiện nay cũng đang gặp một số khó khăn về phí gia nhập, thị trường và nhận biết của cộng đồng. Mục tiêu của nghiên cứu này là đánh giá quyết định tham gia mô hình thương mại công bằng của nông hộ sản xuất cà phê tại xã Xuân Trường, TP. Đà Lạt, tỉnh Lâm Đồng, từ đó đề xuất một số giải pháp nhằm nâng cao khả năng tham gia mô hình thương mại công bằng trong canh tác cà phê của nông hộ. 


\section{Cơ Sở Lý Luận và Phương Pháp Nghiên Cứu}

\subsection{Tổng quan tài liệu}

Thương mại công bằng tạo cho nông dân cơ hội công bằng để cải thiện vị thế thị trường, các tiêu chuẩn dành cho người sản xuất nhỏ gồm tiêu chí về kinh tế, xã hội và môi trường. Thương mại công bằng đóng góp vào tiềm năng phát triển cũng như tạo điều kiện cho các nhóm người sản xuất thiết lập cơ chế dân chủ và quản trị minh bạch (PPFTV, 2011). Tại Lâm Đồng, HTX Cầu Đất - Xuân Trường đã được cấp chứng nhận thương mại công bằng của tổ chức Quốc tế, sản xuất cà phê công bằng là khi HTX có thu nhập, sẽ trích từ 20 - 30\% để hỗ trợ cộng đồng xung quanh. Nông hộ khi tham gia mô hình phải tuân thủ quy trình canh tác không dùng phân hoá học, không sử dụng thuốc trừ sâu rệp, thu hoạch khi quả chín đạt trên $90 \%$ để đảm bảo cho chất lượng cà phê ngon nhất.

Trong ngành hàng cà phê, việc nông hộ tham gia sản xuất theo tiêu chuẩn $(4 \mathrm{C}$, UTZ, Rainforest Alliance, thương mại công bằng) sẽ mang lại những lợi ích nhất định như tăng thu nhập vì đã giảm được chi phí đầu vào và tăng hệ số $\mathrm{BCR}$ (Nguyen \& ctv., 2017; Rosalien \& ctv., 2018), tạo vùng nguyên liệu ổn định, nguồn cà phê xuất khẩu chất lượng cao, có thương hiệu (Nguyen, 2013). Tuy nhiên, những nghiên cứu khác đã chỉ ra không thấy có mối liên hệ giữa chứng nhận thương mại công bằng và thu nhập nông hộ hay giá cả tốt hơn (Ruben \& Fort, 2012), ngược lại nông dân sản xuất cà phê hữu cơ và cà phê có tín chỉ thương mại công bằng đã trở nên nghèo hơn so với các nhà sản xuất thông thường (Beuchelt \& Zeller, 2011), nhiều nông hộ thấy lợi ích trực tiếp tương đối hạn chế vì không phải tất cả sản phẩm của họ được bán theo các điều khoản thương mại công bằng (Elliott, 2012). Mặt khác, các nghiên cứu đã chỉ ra khả năng tham gia của nông hộ vào một mô hình sản xuất nông nghiệp chịu ảnh hưởng tích cực từ các yếu tố như trình độ học vấn, tuổi chủ hộ, kinh nghiệm, quy mô sản xuất, năng lực tài chính, tham gia khuyến nông (Do \& Tran, 2013; Nguyen \& La, 2014; Nguyen \& ctv., 2017), thông tin về kỹ thuật sản xuất nông nghiệp bền vững (Rigbya \& Caceresb, 2001), lợi nhuận (Tran \& ctv., 2019). Tuy nhiên, quá trình tham gia đang gặp rất nhiều khó khăn vì lợi ích do mô hình mang lại chưa đủ hấp dẫn nên rất dễ bị phá vỡ (Tran \& ctv., 2016).

\subsection{Nguồn số liệu}

Số liệu được thu thập từ 222 nông hộ canh tác cà phê (8/2019) tại xã Xuân Trường, TP. Đà Lạt. Đây là khu vực sản xuất cà phê với thương hiệu cà phê Cầu Đất và một trong những địa bàn có triển khai mô hình thương mại công bằng trong tỉnh Lâm Đồng. Số liệu được thu thập thông qua phỏng vấn trực tiếp bằng bảng câu hỏi. Ngoài ra, còn thu thập các thông tin thứ cấp từ nhiều nguồn khác nhau, bao gồm các tài liệu, các báo cáo, các nghiên cứu trong và ngoài nước được thu thập qua các nguồn khác nhau để phục vụ cho nghiên cứu. Các thông tin đã thu thập được tổng hợp, tính toán và phân tích bằng phần mềm Excel và Limdep 9.0.

\subsection{Phương pháp phân tích và xử lý số liệu}

Trong nghiên cứu này, phương pháp hồi quy logit được sử dụng để đánh giá mức sẵn lòng tham gia mô hình thương mại công bằng của nông hộ trong sản xuất cà phê. Mô hình dự đoán và giải thích mối quan hệ của các biến trong các lĩnh vực khác nhau như kinh doanh, kinh tế, giáo dục, chăm sóc sức khoẻ, cũng như trong lĩnh vực nông nghiệp (Pannapa \& Dennis, 2015). Mô hình hồi quy logit được thể hiện như sau:

$$
\begin{aligned}
& \operatorname{Logit}(\mathrm{P})=\operatorname{Ln}\left(\frac{\mathrm{p}}{1-\mathrm{p}}\right)=\beta_{0}+\beta_{1} \mathrm{X}_{1}+\beta_{2} \mathrm{X}_{2} \\
& +\ldots+\beta_{\mathrm{n}} \mathrm{X}_{\mathrm{n}}
\end{aligned}
$$

Các hệ số hồi qui sẽ được ước lượng bằng phương pháp ước lượng hợp lý cực đại (Maximum Likelihood Estimation). Giá trị $\mathrm{P}_{\mathrm{i}}$ xác suất nông hộ thứ i tham gia mô hình thương mại công bằng $(\mathrm{P}=1$ : hộ tham gia mô hình thương mại; $\mathrm{P}=0$ : hộ không tham gia mô hình thương mại công bằng), nên mô hình được viết lại:

$$
\mathrm{P}_{\mathrm{i}}=\frac{\mathrm{e}^{\beta_{0}+\beta_{1} \mathrm{X}_{1}+\beta_{2} \mathrm{X}_{2}+\ldots+\beta_{\mathrm{k}} \mathrm{X}_{\mathrm{k}}}}{1+\mathrm{e}^{\beta_{0}+\beta_{1} \mathrm{X}_{1}+\beta_{2} \mathrm{X}_{2}+\ldots+\beta_{\mathrm{k}} \mathrm{X}_{\mathrm{k}}}}
$$

$\mathrm{X}_{\mathrm{i}}$ là biến độc lập với $\mathrm{X}_{1}$ tuổi chủ hộ (năm); $\mathrm{X}_{2}$ trình độ học vấn của chủ hộ (năm); $\mathrm{X}_{3}$ kinh nghiệm sản xuất cà phê của hộ (năm); $\mathrm{X}_{4}$ diện tích trồng cà phê (ha); $\mathrm{X}_{5}$ lợi nhuận (1000 đ/ha); $\mathrm{X}_{6}$ nhận thức của hộ về thương mại công bằng (sử dụng thang đo Likert để đo lường nhận thức của hộ); $\mathrm{X}_{7}$ giá bán cà phê mong muốn khi tham gia mô hình thương mại công bằng $(1000 \mathrm{~d} / \mathrm{kg})$; $\mathrm{D}_{1}$ giới tính chủ hộ (1: nam, 0 : nữ); $\mathrm{D}_{2}$ khuyến nông( 0 : không tham gia khuyến nông, 1 : tham gia khuyến nông). Các biến độc lập và kỳ vọng dấu trong mô hình logit được mô tả ở Bảng 1. 
Bảng 1. Các biến độc lập và kỳ vọng dấu trong mô hình logit

\begin{tabular}{|c|c|c|}
\hline Tên biến & Kỳ vọng dấu & Giải thích \\
\hline$\overline{\mathrm{X}_{1} \text { (Tuổi chủ hộ) }}$ & $(-)$ & $\begin{array}{l}\text { Chủ hộ càng lớn tuổi thì sẽ gặp nhiều khó khăn nên } \\
\text { khả năng tham gia mô hình càng thấp }\end{array}$ \\
\hline 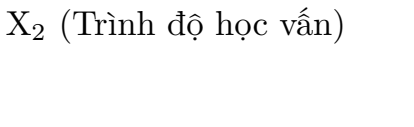 & $(+)$ & $\begin{array}{l}\text { Trình độ học vấn của chủ hộ càng cao thì khả năng } \\
\text { nhận biết rõ những lợi ích của mô hình mang lại nên } \\
\text { khả năng tham gia càng cao }\end{array}$ \\
\hline $\mathrm{X}_{3}$ (Kinh nghiệm) & $(-)$ & $\begin{array}{l}\text { Chủ hộ có kinh nghiệm lâu năm thì khả năng nhận } \\
\text { biết rủi ro thường cao nên xác suất chọn mồ hình } \\
\text { thấp }\end{array}$ \\
\hline $\mathrm{X}_{4}$ (Diện tích cà phê) & $(+)$ & $\begin{array}{l}\text { Diện tích trồng cà phê càng lớn thì dễ áp dụng tiến } \\
\text { bộ kỹ thuật (máy móc, trang thiết bị hiện đại) vào } \\
\text { săn xuất nên khả năng chọn mô hình cao }\end{array}$ \\
\hline X5 (Lợi nhuận) & $(+)$ & $\begin{array}{l}\text { Hộ trồng cà phê có lợi nhuận tốt thì có khả năng đầu } \\
\text { tư trang thiết bị máy móc phục vụ cho sản xuất của } \\
\text { hộ được tốt hơn, do vậy khả năng tham gia mô hình } \\
\text { càng cao }\end{array}$ \\
\hline $\begin{array}{l}\mathrm{X}_{6} \text { (Nhận thức về thương } \\
\text { mại công bằng) }\end{array}$ & $(+)$ & $\begin{array}{l}\text { Nông hộ có nhận thức về lợi ích mà thương mại công } \\
\text { bằng mang lại rõ ràng thì khả năng tham gia mô } \\
\text { hình càng cao }\end{array}$ \\
\hline X 7 (Giá bán mong chờ) & $(+)$ & $\begin{array}{l}\text { Khi tham gia mô hình thì nông hộ luôn mong muốn } \\
\text { giá bán cà phê cao hơn so với giá cà phê thị trường }\end{array}$ \\
\hline $\mathrm{D}_{1}$ (Giới tính) & $(+)$ & $\begin{array}{l}\text { Nếu giới tính chủ hộ là nam thì khả năng tham mô } \\
\text { hình sẽ cao hơn chủ hộ là nữ }\end{array}$ \\
\hline 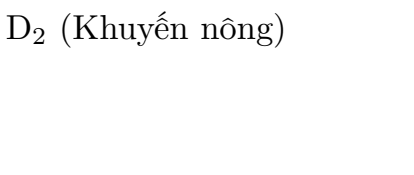 & $(+)$ & $\begin{array}{l}\text { Nếu nông hộ có tham gia tập huấn khuyến nông thì } \\
\text { có cơ hội tiếp cận các chương trình hỗ trợ, tiến bộ kỹ } \\
\text { thuật trong sản xuất hộ hơon những hộ không tham } \\
\text { gia khuyến nông }\end{array}$ \\
\hline
\end{tabular}

\section{Kết Quả và Thảo Luận}

\subsection{Một số đặc điểm về nhân khẩu học và xã hội học của hộ điều tra}

Nghiên cứu tiến hành phỏng vấn 194 hộ sản xuất cà phê không tham gia và 28 hộ đã tham gia mô hình. Kết quả thống kê từ Bảng 2 cho thấy đối tượng khảo sát khá đa dạng và phong phú về tuổi tác cũng như trình độ học vấn. Độ tuổi trung bình của chủ hộ vào khoảng 50 tuổi (trong đó mức tuổi từ 40 đến 50 tuổi chiếm tỷ trọng cao nhất $35,7 \%$ (hộ tham gia), và $33,0 \%$ (hộ không tham gia) từ 50 đến 60 tuổi. Ở độ tuổi này, nông hộ vẫn còn đủ sức khoẻ để trực tiếp tham gia quá trình sản xuất cà phê.

Đồng thời, trình độ học vấn của nông hộ chủ yếu là trung học cơ sở và trung học phổ thông, điều này tạo nhiều thuận lợi cho việc nắm bắt thông tin thị trường cũng như tiếp cận khoa học kỹ thuật khi tham gia mô hình. Bên cạnh đó, kinh nghiệm là một trong những yếu tố có ảnh hưởng nhất định đến sản xuất, dựa vào kết quả thống kê cho thấy, kinh nghiệm trong sản xuất cà phê của nông hộ trên 20 năm chiếm $57,1 \%$ (hộ tham gia) và $64 \%$ (hộ không tham gia) với quy mô sản xuất chủ yếu ở mức 1,5 - 2 ha.

Bên cạnh đó, Bảng 3 chỉ ra hình thức canh tác của nông hộ trồng cà phê, với hình thức trồng xen canh với cây ăn trái chiếm tỷ trọng cao nhất 53,6\% (Hộ đã tham gia), và 59,3\% (Hộ không tham gia). Hình thức xen canh giữa cây cà phê với cây ăn trái đã giúp cây cà phê tăng khả năng chịu hạn và giảm đáng kể lượng nước tưới vào mùa khô.

\subsection{Phân tích các yếu tố ảnh hưởng đến khả năng tham gia thương mại công bằng của nông hộ trong sản xuất cà phê}

\subsubsection{Nhận thức của nông hộ về lợi ích của thương mại công bằng trong canh tác cà phê}

Bảng 4 thể hiện nhận thức của nông hộ về các lợi ích khi tham gia thương mại công bằng. Kết 
Bảng 2. Thông tin chung về đối tượng phỏng vấn

\begin{tabular}{|c|c|c|c|c|}
\hline \multirow{2}{*}{ Chỉ tiêu } & \multicolumn{2}{|c|}{$\begin{array}{c}\text { Nhóm hộ tham gia } \\
\text { thương mại công bằng }\end{array}$} & \multicolumn{2}{|c|}{$\begin{array}{c}\text { Nhóm hộ không tham gia } \\
\text { thương mại công bằng }\end{array}$} \\
\hline & Tần số ( Hộ) & Tỷ lệ $(\%)$ & Tần số ( Hộ) & Tỷ lệ (\%) \\
\hline \multicolumn{5}{|l|}{ 1. Giới tính chủ hộ } \\
\hline Nam & 17 & 60,7 & 135 & 69,6 \\
\hline Nư & 11 & 39,3 & 59 & 30,4 \\
\hline \multicolumn{5}{|l|}{ 2. Tuổi chủ hộ } \\
\hline$\leq 30$ tuổi & 3 & 10,6 & 5 & 2,6 \\
\hline 30 tuổi - 40 tuổi & 5 & 17,9 & 31 & 16,0 \\
\hline 40 tuổi - 50 tuổi & 10 & 35,7 & 54 & 27,8 \\
\hline 50 tuổi - 60 tuổi & 5 & 17,9 & 64 & 33,0 \\
\hline$>60$ tuổi & 5 & 17,9 & 40 & 20,6 \\
\hline \multicolumn{5}{|l|}{ 3. Trình độ học vấn } \\
\hline Mù chữ & 0 & 0 & 2 & 1 \\
\hline Tiểu học & 5 & 17,9 & 18 & 9,3 \\
\hline Trung học cơ sở & 10 & 35,7 & 102 & 52,6 \\
\hline Trung học phổ thông & 13 & 46,4 & 69 & 35,6 \\
\hline Cao đẳng - Đại học & 0 & 0 & 3 & 1,5 \\
\hline \multicolumn{5}{|l|}{ 4. Kinh nghiệm } \\
\hline$\leq 5$ năm & 3 & 10,7 & 6 & 3,1 \\
\hline 5 năm - 10 năm & 3 & 10,7 & 16 & 8,2 \\
\hline 10 năm - 15 năm & 2 & 7,2 & 26 & 13,4 \\
\hline 15 năm - 20 năm & 4 & 14,3 & 22 & 11,3 \\
\hline$>20$ năm & 16 & 57,1 & 124 & 64 \\
\hline \multicolumn{5}{|l|}{ 5. Qui mô sản xuất } \\
\hline$\leq 5.000 \mathrm{~m}^{2}$ & 3 & 10,7 & 12 & 6,2 \\
\hline 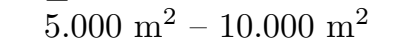 & 5 & 17,9 & 37 & 1,1 \\
\hline $10.000 \mathrm{~m}^{2}-15.000 \mathrm{~m}^{2}$ & 6 & 21,4 & 21 & 10,8 \\
\hline$>15.000 \mathrm{~m}^{2}$ & 14 & 50,0 & 124 & 63,9 \\
\hline
\end{tabular}

Bảng 3. Hình thức canh tác cà phê của nông hộ

\begin{tabular}{lccccc}
\hline \multirow{2}{*}{ Chỉ tiêu } & \multicolumn{2}{c}{$\begin{array}{c}\text { Nhóm hộ tham gia } \\
\text { thương mại công bằng }\end{array}$} & \multicolumn{2}{c}{$\begin{array}{c}\text { Nhóm hộ không tham gia } \\
\text { thương mại công bằng }\end{array}$} \\
\cline { 2 - 6 } & Tần số ( Hộ) & Tỷ lệ $(\%)$ & Tần số ( Hộ) & Tỷ lệ $(\%)$ \\
\hline Độc canh & 11 & 39,3 & 71 & 36,6 \\
Xen canh với cây ăn trái & 15 & 53,6 & 115 & 59,3 \\
Xen canh với cây CN & 2 & 7,1 & 8 & 4,1 \\
Xen canh với cây rừng & 0 & 0,0 & 0 & 0,0 \\
\hline
\end{tabular}

quả thống kê cho thấy, có sự khác biệt rõ rệt trong nhận thức của nông hộ về những lợi ích mà mô hình thương mại công bằng mang lại.

Nhóm hộ tham gia cho rằng việc nâng cao trình độ kĩ thuật, tạo mối quan hệ thương mại lâu dài, tạo công ăn việc làm, hiệu quả kinh tế đóng vai trò rất quan trọng, đặc biệt họ nhận thức rất rõ về tầm quan trọng trong bảo vệ môi trường xung quanh $(4,21)$ và đảm bảo sức khỏe trong sản xuất $(4,00)$. Trong khi nhóm hộ không tham gia thương mại công bằng thì mức nhận thức về lợi ích chỉ ở mức trung bình, nhưng họ cũng đánh giá rất cao về bảo vệ môi trường xung quanh, đảm bảo sức khỏe trong sản xuất và nâng cao trình độ kỹ thuật. 
Bảng 4. Các lợi ích khi tham gia sản xuất thương mại công bằng (TMCB)

\begin{tabular}{|c|c|c|c|c|}
\hline \multirow{3}{*}{ Khoản mục } & \multicolumn{2}{|c|}{$\begin{array}{l}\text { Nhóm hộ tham } \\
\text { gia TMCB }\end{array}$} & \multicolumn{2}{|c|}{$\begin{array}{l}\text { Nhóm hộ không } \\
\text { tham gia TMCB }\end{array}$} \\
\hline & Trung & Độ lệch & Trung & Độ lệch \\
\hline & bình & chuẩn & bình & chuẩn \\
\hline Tạo công ăn việc làm & 3,79 & 0,157 & 3,35 & 0,057 \\
\hline Công khai minh bạch & 3,71 & 0,134 & 3,21 & 0,057 \\
\hline Nâng cao trình độ kĩ thuật & 3,82 & 0,115 & 3,52 & 0,054 \\
\hline Công bằng trong giá cả & 3,50 & 0,181 & 3,29 & 0,066 \\
\hline Bình đẳng về giới & 3,68 & 0,126 & 3,22 & 0,052 \\
\hline Môi trường làm việc an toàn đảm bảo sức khỏe & 4,00 & 0,126 & 3,53 & 0,051 \\
\hline Bảo vệ môi trường & 4,21 & 0,127 & 3,56 & 0,052 \\
\hline Được hỗ trợ & 3,71 & 0,177 & 3,15 & 0,069 \\
\hline Hiệu quả kinh tế & 3,75 & 0,175 & 3,41 & 0,068 \\
\hline Mối quan hệ thương mại lâu dài, bền vững & 3,93 & 0,125 & 3,30 & 0,064 \\
\hline
\end{tabular}

3.2.2. Mô hình hồi quy các yếu tố ảnh hưởng đến khả năng tham gia thương mại công bằng trong sản xuất cà phê

Bảng 5 trình bày kết quả hồi quy mô hình logit. Những hệ số trình bày trong Bảng 5 thể hiện hệ số hồi quy và tác động biên của các yếu tố đến sự tham gia của nông hộ sản xuất cà phê trong mô hình thương mại công bằng. Hệ số hồi quy của một yếu tố càng cao chứng tỏ tác động biên của yếu tố đó càng lớn. Hệ số $\mathrm{R}^{2}$ của mô hình là $59,27 \%$ và $P(\mathrm{~F}$-stat $)=0,000$ nhỏ hơn rất nhiều so với mức $\alpha=5 \%$, điều này cho thấy sự phù hợp của mô hình hồi quy logit và các biến trong mô hình giải thích được 59,27\% đến sự tham gia của nông hộ sản xuất cà phê trong mô hình thương mại công bằng, xác suất nông hộ tham gia mô hình là 14,43\% $\left(\mathrm{Y}_{1} / \mathrm{Y}_{0}\right)$.

Kết quả hồi quy từ Bảng 5 cho thấy, các biến như tuổi chủ hộ, trình độ học vấn, diện tích canh tác, lợi nhuận, nhận thức về thương mại công bằng, giá bán mong chờ và khuyến nông có ảnh hưởng đến sự tham gia mô hình thương mại công bằng của nông hộ trồng cà phê. Phương trình hồi quy được thiết lập như sau:

$$
\begin{aligned}
& \log _{\mathrm{e}}\left(\frac{\mathrm{P}(\mathrm{Y}=1)}{\mathrm{P}(\mathrm{Y}=0)}\right)=-21,331-0,074 \mathrm{X}_{1}+ \\
& 1,301 \mathrm{X}_{2}+0,077 \mathrm{X}_{3^{-}}-0,946 \mathrm{X}_{4}+0,459 \mathrm{X}_{5}+ \\
& 1,941 \mathrm{X}_{6}+0,483 \mathrm{X}_{7}-0,449 \mathrm{D}_{1}-0,728 \mathrm{D}_{2}
\end{aligned}
$$

Trong mô hình này, biến trình độ học vấn $\left(\mathrm{X}_{2}\right)$, biến lợi nhuận $\left(\mathrm{X}_{4}\right)$, biến nhận thức về thương mại công bằng $\left(\mathrm{X}_{6}\right)$ và biến mức giá bán kỳ vọng $\left(\mathrm{X}_{7}\right)$ có ảnh hưởng tích cực đến sự tham gia mô

\begin{tabular}{|c|c|c|}
\hline Diễn giải & Hệ số ${ }^{1}$ & $\begin{array}{c}\text { Tác } \\
\text { động } \\
\text { biên }\end{array}$ \\
\hline $\mathrm{C}$ & $-21,331$ & $-0,151$ \\
\hline (Hằng số) & $(0,000)$ & \\
\hline $\mathrm{X}_{1}$ & $-0,074^{*}$ & \\
\hline (Tuổi chủ hô̂) & $(0,091)$ & \\
\hline $\mathrm{X}_{2}$ & $1,301^{* * *}$ & 0,0092 \\
\hline (Trình độ học vấn) & $(0,000)$ & \\
\hline $\begin{array}{c}\dot{\mathrm{X}}_{3} \\
(\text { Kinh nghiệm) }\end{array}$ & $\begin{array}{l}0,077^{\mathrm{ns}} \\
(0,208)\end{array}$ & 0,0005 \\
\hline $\begin{array}{c}\mathrm{X}_{4} \\
\text { (Diên tích trồng cà phê) }\end{array}$ & $\begin{array}{c}-0,946^{* *} \\
(0,036)\end{array}$ & $-0,0067$ \\
\hline $\mathrm{X}_{5}$ & $0,458^{*}$ & 0,0032 \\
\hline $\begin{array}{l}\text { (Lợi nhuận) } \\
\mathrm{X}_{6}\end{array}$ & $(0,088)$ & \\
\hline $\begin{array}{l}\text { (Nhận thức về } \\
\text { thương mại công bằng) }\end{array}$ & $\begin{array}{c}1,914^{* * *} \\
(0,007)\end{array}$ & 0,0136 \\
\hline $\begin{array}{c}\mathrm{X}_{7} \\
\text { (Giá bán mong chờ) }\end{array}$ & $\begin{array}{c}0,483^{* *} \\
(0,028)\end{array}$ & 0,0034 \\
\hline $\begin{array}{c}\mathrm{D}_{1} \\
(\text { Giới tính })\end{array}$ & $\begin{array}{c}-0,449^{\text {ns }} \\
(0,497)\end{array}$ & $-0,0035$ \\
\hline $\mathrm{D}_{2}$ & $-0,728^{*}$ & -0.0054 \\
\hline (Khuyến nông) & $(0,081)$ & \\
\hline Log likelihood & $-34,258$ & \\
\hline McFadden R-squared & 0,5927 & \\
\hline Probability(LR stat) & 0,0000 & \\
\hline
\end{tabular}
hình thương mại công bằng trong sản xuất cà
Bảng 5. Kết quả ước lượng mô hình hồi quy logit

Nguồn: Tính toán từ kết suất phần mềm Limdep 9 . ${ }^{1}$ Số trong ngoặc là giá trị $P$.

***,**,* lần lượt là mức ý nghĩa $1 \%, 5 \%$ và $10 \%$; ns không có ý nghĩa thống kê.

phê của nông hộ. Khi nhận thức về thương mại 
công bằng của nông hộ tăng thêm 1 điểm thì khả năng tham gia mô hình của nông hộ sẽ tăng lên $1,36 \%$, điều này là do việc sản xuất cà phê trong mô hình thương mại công bằng có môi trường sản xuất được kiểm soát rất chặt chẽ nên việc nâng cao nhận thức của nông hộ trong sử dụng các yếu tố đầu vào là rất cần thiết. Bên cạnh đó, giá bán cà phê là yếu tố mà nông hộ rất mong đợi khi tham gia mô hình thương mại công bằng, nông hộ luôn mong muốn bán được cà phê với giá cao hơn khi tham gia mô hình.

Mặt khác, khi có sự gia tăng các biến như tuổi chủ hộ, diện tích canh tác thì sẽ làm giảm khả năng tham gia mô hình thương mại công bằng của nông hộ. Khi phần lớn nông hộ sản xuất cà phê tại địa bàn với quy mô nhỏ và phân tán nên gặp nhiều khó khăn khi tham gia mô hình. Đây rất có thể là nguyên nhân dẫn đến tăng diện tích sản xuất sẽ làm giảm khả năng tham gia mô hình thương mại công bằng.

Bảng 6 thể hiện kết quả dự đoán trong mô hình, với kết quả dự đoán đúng là $94,1 \%$. Điều này có nghĩa các hệ số hồi quy trong mô hình là thích hợp cho việc giải thích sự tham gia của nông hộ sản xuất cà phê trong mô hình thương mại công bằng. Trong số 194 hộ không tham gia mô hình dự đoán được 191 (86,0\%) hộ đúng với thực tế, trong số 28 hộ tham gia mô hình dự đoán được $18(8,1 \%)$ hộ đúng với thực tế.

Bảng 6. Kết quả dự đoán của mô hình

\begin{tabular}{cccc}
\hline \multirow{2}{*}{ Chỉ tiêu } & \multirow{2}{*}{ Số hộ } & \multicolumn{2}{c}{ Dự đoán của mô hình } \\
\cline { 3 - 4 } & 194 & $\mathrm{Y}=0$ & $\mathrm{Y}=1$ \\
\hline $\mathrm{Y}=0$ & $(87,4 \%)$ & $(86,0 \%)$ & $(1,4 \%)$ \\
& 28 & 10 & 18 \\
$\mathrm{Y}=1$ & $(12,6 \%)$ & $(4,5 \%)$ & $(8,1 \%)$ \\
\hline Tổng & 222 & \multicolumn{2}{c}{$94,1 \%$} \\
\hline \multicolumn{2}{c}{ Nguồn: Tính toán từ kết suất phần mềm Limdep 9.}
\end{tabular}

\subsection{3. Đề xuất một số giải pháp nhằm nâng cao khả năng tham gia liên kết}

Qua kết quả phân tích thì để nâng cao khả năng tham gia của nông hộ trong mô hình thương mại công bằng thì cần một số giải pháp như:

Tiềm năng chứng nhận thương mại công bằng còn rất nhiều cơ hội bởi Lâm Đồng có sản lượng cà phê rất lớn. Do vậy, hợp tác xã cần phải xây dựng và triển khai các chương trình hành động nhằm nâng cao nhận thức của nông hộ về lợi ích lâu dài của thương mại công bằng. Mặt khác, tạo cơ hội tham gia chứng nhận thương mại công bằng cho những hộ chưa có khả năng tham gia mô hình.

Nông hộ phải thay đổi tư duy trong sản xuất theo hướng nâng cao chất lượng sản phẩm nhằm mục tiêu phát triển cà phê bền vững. Việc tham gia mô hình thương mại công bằng sẽ giúp cho nông hộ hạn chế những rủi ro trong sản xuất và tiêu thụ, gắn kết giữa công tác thu hoạch với chế biến, cũng như giảm thiểu được sự ép giá của thương lái khi vào vụ thu hoạch.

\section{Kết Luận}

Ngành cà phê Việt Nam, với đặc thù là một ngành nông nghiệp có số lượng lớn doanh nghiệp quy mô nhỏ và vừa, sức cạnh tranh yếu, thương mại công bằng là một kênh xúc tiến thương mại hiệu quả đối với những doanh nghiệp yếu thế muốn xâm nhập và mở rộng thị trường. Khi tham gia liên kết trong sản xuất cà phê, nông hộ sẽ dẽ̃ tiếp cận với thị trường, với tiến bộ kỹ thuật mới qua việc chuyển giao từ các doanh nghiệp. Nghiên cứu đã sử dụng hàm hồi quy logit theo phương pháp ước lượng cực đại (MLE) để ước tính khả năng tham gia liên kết trong sản xuất cà phê của nông hộ. Kết quả ước lượng cho thấy, xác suất nông hộ tham gia sản xuất cà phê theo mô hình thương mại công bằng là 14,43\%. Bên cạnh đó, kết quả phân tích chỉ ra các yếu tố như tuổi chủ hộ, trình độ học vấn, diện tích canh tác, lợi nhuận, nhận thức về thương mại công bằng, giá bán mong chờ và khuyến nông có ảnh hưởng đến sự tham gia mô hình thương mại công bằng của nông hộ trồng cà phê, trong đó biến nhận thức về thương mại công bằng và giá bán mong chờ có ảnh hưởng mạnh nhất đến khả năng tham gia mô hình thương mại công bằng trong sản xuất cà phê của nông hộ.

\section{Tài Liệu Tham Khảo (References)}

Beuchelt, T. D., \& Zeller, M. (2011). Profits and poverty: Certification's troubled link for Nicaragua's organic and fairtrade coffee producers. Ecological Economics 7, 1316-1324.

Do, G. Q., \& Tran, T. T. (2013). Evaluating probability of joining contract farming of farmer in northern hilly and mountainous region: a case study of tea farmer in Tuyen Quang province. Journal of Agriculture \& Rural Development 11(3), 447-457.

Elliott, K. A. (2012). Is my fair trade coffee really fair? Trends and challenges in fair trade certification. CGD Policy Paper 017. Washington DC: Center for 
Global Development. Retrieved August 20, 2019, from http://www.cgdev.org/content/publications/detail/14 26831 .

Le, H. C. (2017). Evaluating the sustainability of the model of fair trade coffee in Thuan An commune, Dak Mil district, Dak Nong (Unpublished master's thesis). Vietnam National University, Hanoi, Vietnam.

MARD (Ministry of Agriculture and Rural Development). (2014). Report No. 3147/BC-BNN dated on August 1, 2014, approving the project of sustainable development of coffee industry until 2020. Ha Noi, Vietnam: MARD Office.

Nguyen, G. N. T., \& Tapan, S. (2018). Sustainable coffee supply chain management: a case study in Buon Me Thuot City, Daklak, Vietnam. International Journal of Corporate Social Responsibility 3, 1-17.

Nguyen, H. D., Tran, T. Q., \& Bui, K. H. T. (2017). Evaluation of factors affecting ability to engage linkage in maize consumption for farmer households in Son La province. Vietnam Journal Agriculture and Science 15(4), 529-536.

Nguyen, T., \& La, K. S. (2014). Research on farmer's economic cooperation need in the Mekong river delta. Journal of Agriculture \& Rural Development 1, 10-16.

Nguyen, T. T. (2013). Investigation and assessing the status of raw material area serving coffee bean processing industry in Dak Lak province (Unpublished master's thesis). The University of Tay Nguyen, Tay Nguyen, Vietnam.

Pannapa, C., \& Dennis, K. J. L. (2015). Selection of multinomial logit models via association rules analysis. Advanced Review 5, 68-77.
PPFTV (Project Promoting Fair Trade in Vietnam). (2011). General standard of fair trade for small producers' organization. Retrieved August 1, 2019, from http://fairtrade.org.vn.

Tran, N. H., Le, V., \& Tran, L. D. (2019). Evaluation of probability of linkages between enterprises and farmer's potatoes in Lam Dong province. The Journal of Agriculture and Development 18(1), 1-8.

Tran, T. Q., Le, C. T. M., Do, G. Q., Bui, D. B., Bui, L. T. M., Nguyen, O. Q., Le, H. T T., Tran, Y. N. T., \& Pham, D. K. (2016). A final report on establishing the process of cooperative production in the use of corn for animal feed. Son La, Vietnam: Department of Science and Technology of Son La province.

Rigbya, D., \& Caceresb, D. (2001). Organic farming and the sustainability of agricultural systems. Agricultural Systems 68(1), 21-40.

Rosalien, E. J., Maria, J. R., René, G. A. B., Martin, J., \& Pita, A. V. (2018). Effects of shade and input management on economic performance of small-scale Peruvian coffee systems. Agricultural Systems 162, 179-190.

Ruben, R., \& Fort, R. (2012). The impact of fair trade certification for coffee farmers in Peru. World Development 40(3), 570-582.

Vicofa (Vietnam Coffee - Cocoa Association). (2018). Coffee import and export situation. Retrieved August 1, 2019, from http://www.vicofa.org.vn/. 